\title{
Cryo-SEM Methodology of Arabidopsis thaliana Stem Using High-Pressure Freezing
}

\author{
Yun Joung Choi, Kyung Hwan Lee ${ }^{1}$, A Reum Je, \\ Heesu Chae, Jihoon Jang ${ }^{2}$, Eunji Lee ${ }^{2}$, \\ Hee-Seok Kweon* \\ Division of Electron Microscopic Research, Korea Basic \\ Science Institute, 169-148 Gwahangno, Daejeon 305-806, \\ Korea \\ ${ }^{1}$ Department of Cell Biology, U. Mass. Medical School, \\ 55 Lake Ave. North Worcester, MA 01655, USA \\ ${ }^{2}$ Graduate School of Analytical Science and Technology, \\ Chungnam National University, 79 Daehangno, \\ Daejeon 305-764, Korea \\ (Received June 11, 2012; Revised June 27, 2012; \\ Accepted June 27, 2012)
}

ABSTRACT : The scanning electron microscopy is an ideal technique for examining plant surface at high resolution. Most hydrate samples, however, must be fix and dehydrate for observation in the scanning electron microscope. Because the microscopes operate under high vacuum, most specimens, especially biological samples, cannot withstand water removal by the vacuum system without morphological distortion. Cryo-techniques can observe in their original morphology and structure without various artifacts from conventional sample preparation. Rapid cooling is the method of choice for preparing plant samples for scanning electron microscopy in a defined physiological state. As one of cryo-technique, highpressure freezing allows for fixation of native non-pretreated samples up to $200 \mu \mathrm{m}$ thick and $2 \mathrm{~mm}$ wide with minimal or no ice crystal damage for the freezing procedure. In this study, we could design to optimize structural preservation and imaging by comparing cryo-SEM and convention SEM preparation, and observe a fine, well preserved Arabidopsis stem's inner ultrastructure using HPF and cryo-SEM. These results would suggest a useful method of cryo-preparation and cryo-SEM for plant tissues, especially intratubule and vacuole rich structure. (최윤정, 이경환, 제아름, 채희수, 장지훈, 이은지, 권희석: 고압동결고정을 이용한 애기장대 줄기 의 cryo-SEM 분석법)

Keywords : High pressure freezing, Cryo-preparation, Cryo-SEM, Freeze fracturing
주사전자현미경 (Scanning electron microscope, SEM) 기법 은 고해상도를 기반으로 시료의 절단 혹은 절삭 등 형태의 변형없이 내외부 표면의 미세구조를 3 차원적으로 분석할 수 있기 때문에 생물 시료의 구조 연구에 다양하게 활용되고 있 다. 그러나 일반적으로 생물 시료들은 상당량의 수분을 함유 하고 있어, 고진공 및 고전압을 사용하는 SEM으로 시료를 직접 관찰하는 것은 특수한 경우를 제외하고는 사실상 불가 능하다. 따라서 시료의 전자선 손상을 막고 구조적 안정성을 확보하기 위해 화학 고정, 탈수, 건조 등 일련의 전처리 과정 을 거쳐 표면 코팅을 한 후 관찰을 하는 것이 일반적이다. 그러나 이러한 전처리 과정은 많은 시간이 소요될 뿐만 아 니라, 일련의 과정에서 사용되는 고정액과 유기용매들과의 cross-link 등에 의한 시료의 구조적 변형을 초래할 수 있다.

최근 개발되고 있는 다양한 동결 기술(cryo-technique) 즉, rapid cooling, fracturing, sectioning 그리고 etching 등의 cryo$\mathrm{SEM}$ 분석을 위한 시료제작 방법 등을 이용할 경우 $-170^{\circ} \mathrm{C}$ 이하의 극저온 처리 방식을 통해 전처리 시간을 단축시킬 수 있다. 또한 화학 고정 과정 중 발생할 수 있는 시료의 구 조적 변형을 최소화시킴으로써 수분을 함유하는 생체 시료 를 자연 상태에 가깝게 분석할 수 있도록 하고 있다. 특히, rapid cooling 법으로 사용되고 있는 high pressure freezing (HPF) 기법은 시료를 약 $2,100 \mathrm{bar}$ 의 고압에서 순간적으로 동결시킴으로써 조직의 구조를 원래의 상태로 유지시킬 수 있는 가장 효과적인 고정 방법으로 알려져 있다. 이 방법은 다른 급속 동결법에 비해 비교적 두꺼운 시편 $(100 \sim 200 \mu \mathrm{m})$ 에 대해서도 얼음 결정에 의한 손상 없이 고정이 가능하여 시료의 미세구조 연구를 위한 이상적인 기법으로 평가 받고 있다(Shimoni and Muller, 1988).

본 연구에서는 $\mathrm{HPF}$ 를 이용한 cryo-SEM 기법과 일반적인 SEM 시료 제작법을 각각 이용하여 애기장대(Arabidopsis thaliana) 줄기의 단면을 비교 분석함으로써 식물의 관상구 조 연구를 위한 효과적인 SEM 전처리 기법을 확립하고자 하였다.

본 실험을 위하여 대표적 모델 식물인 애기장대를 사용하

본 연구는 한국기초과학지원연구원의 자체연구사업(T3221D)과 교육과학기술부 재원으로 한국연구재단(2009, 특화전문대학원 연계 학연협력 사업)의 지원을 받아 수행하였음.

* Correspondence should be addressed to Dr. Hee-Seok Kweon, Division of Electron Microscoipic Research, Korea Basic Science Institute, 169-148 Gwahangno, Yuseong-gu, Daejeon 305-806, Korea. Ph.: (042) 865-3685, Fax: (042) 865-3939, E-mail: hskweon@ kbsi.re.kr 


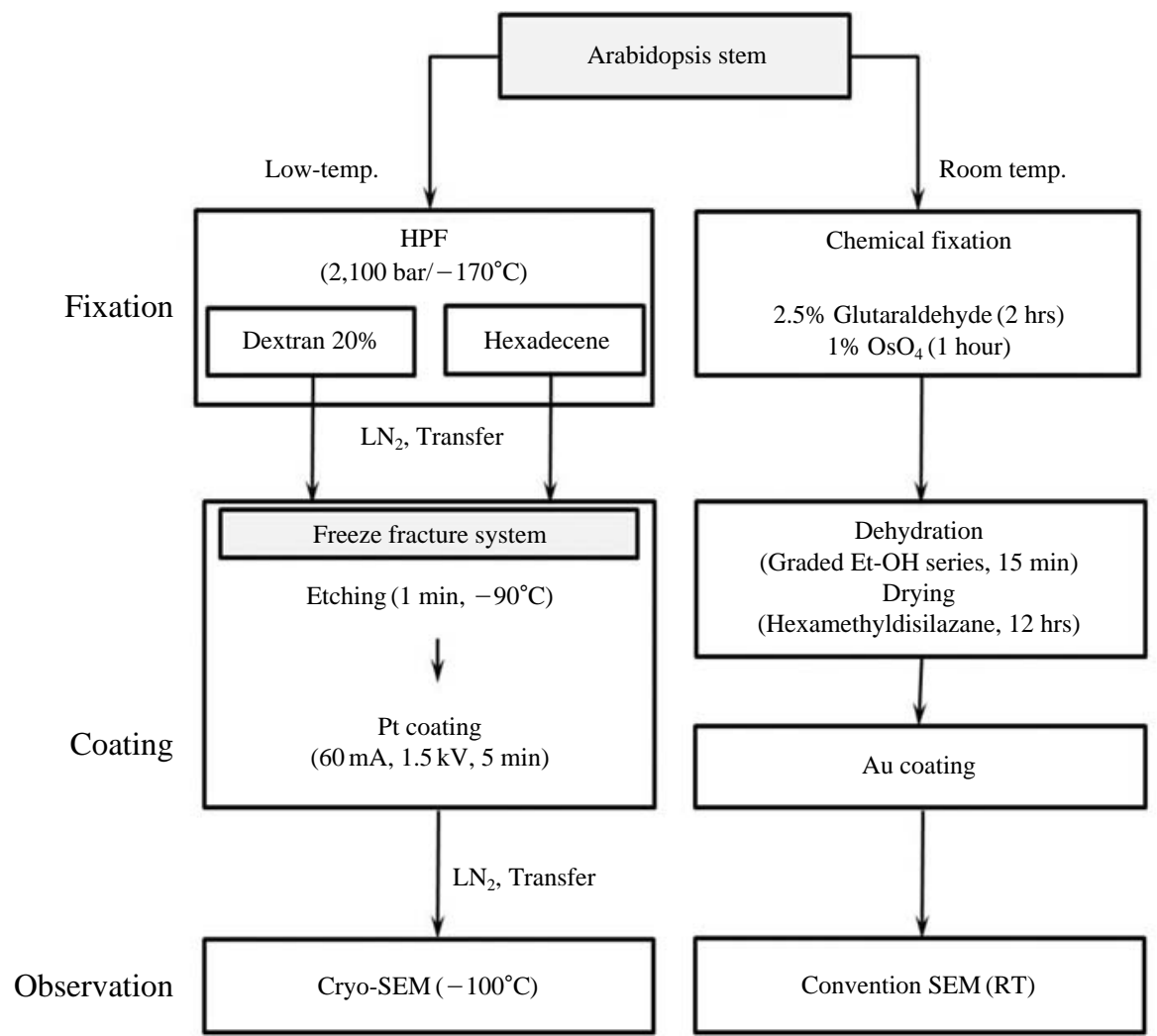

Fig. 1. EM procedures for the exploration of Arabidopsis stem ultrastructure. Schematic representation of the sample preparation steps in convention scanning electron microscope and cryo-scanning electron microscope.

였으며 물관과 체관이 관통하는 줄기 부분을 vibratome 이 용하여 $200 \mu \mathrm{m}$ 이내의 $\mathrm{HPF}$ 허용 두께로 정단면 채취하여 사용하였다. 이들 시료는 각각 일반적인 시료 제작과 동결 시료 제작을 위하여 Fig. 1과 같이 처리한 후 그 결과를 비 교 분석하였다.

일반 시료의 경우 $2.5 \%$ glutaraldehyde 고정액에 2시간 고 정 후, 인산 완충용액 (phosphate buffer, $\mathrm{PB}$ )에 15분씩 2회 세척하고 $1 \%$ 오스뮴산 $\left(\mathrm{OsO}_{4}\right)$ 에 1 시간 동안 고정과 탈수 과정을 거친 후, hexamethyldisilazane (HMDS, SAMCHUN Pure Chemical) 용액으로 12시간 동안 치환하여 사용하였 다. 화학고정을 거친 후 일반적인 SEM 관찰법과 동일하게 금 $(\mathrm{Au})$ 코팅을 한 후 LEO 1455VP(Carl Zeiss. Germany)에 장착한 후 가속전압 $20 \mathrm{kV}$ 에서 이미지를 관찰하였다.

동결 시료의 경우 애기장대 줄기의 고정을 위하여 rapid cooling 법으로 알려진, HPF 장치 (HPM010, Leica, Austria)를 이용하였다. 시료는 $100 \%$ 에탄올 혹은 초음파 세척기를 사 용하여 세척한 지정된 $\mathrm{HPF}$ 용 carrier에 넣을 수 있도록 최 대 직경이 $2 \mathrm{~mm}$, 그리고 최대 두께가 $200 \mu \mathrm{m}$ 가 되도록 준 비하였다. 단면 채취한 애기장대 줄기를 각각 $20 \%$ dextran (Sigma)과 1-hexadecene (Sigma)을 이용하여 종 방향으로 세 운 후 carrier와 시료 사이의 빈 공간은 $20 \%$ dextran과 1- hexadecene으로 채우고 다른 carrier를 이용하여 덮어주었 다. 모든 준비가 완료된 시료는 HPF의 specimen holder로 옮 겨 specimen pressure chamber에 넣고 동결 고정을 실시하 였다. 이때 $\mathrm{HPF}$ 조건은 압력 $2,100 \mathrm{bar}$ 에서 $-170^{\circ} \mathrm{C}$ 이하로 설정하였다. 동결 고정이 끝난 시료는 액체 질소에 옮긴 후 cryo-transfer를 이용하여 freeze fracture system (BAF101, Leica, Austria)으로 옮겼다.

Freeze fracture (FF)를 수행할 때, fracturing 단계에서 knife와 시료는 직각이 되도록 유지한 후 fracture를 실시하 여 양질의 단면 시편을 얻었다. 동결 파쇄시킨 시료는 진공 상태에서 동결 면의 승화를 위해 $-90^{\circ} \mathrm{C}$ 에서 1 분간 etching 을 실시하였다. Etching은 동결된 시료의 내부 구조 및 표면 구조를 분명하게 볼 수 있도록 하는 효과가 있으며 수분을 함유한 생물시료의 경우 $-80^{\circ} \mathrm{C}$ 에서 재결정이 일어나는 것 으로 알려져 있다. 따라서 본 실험에서는 식물체 내 수분의 재결정화를 방지하고 승화의 효과를 극대화하기 위하여 최 적 조건을 시험하여 etching의 시간을 단축시킨 상기 온도 조건을 적용하였다. Etching을 통해 드러난 표면 위에 전도 성을 주기 위하여 백금을 도포하였다 $(1.5 \mathrm{kV}, 60 \mathrm{~mA}, 5 \mathrm{~min})$. 백금 도포가 끝난 시료는 cryo-transfer를 이용해 cryo-SEM 으로 옮겼다. 이때 cryo-transfer는 액체 질소를 이용해 시료 

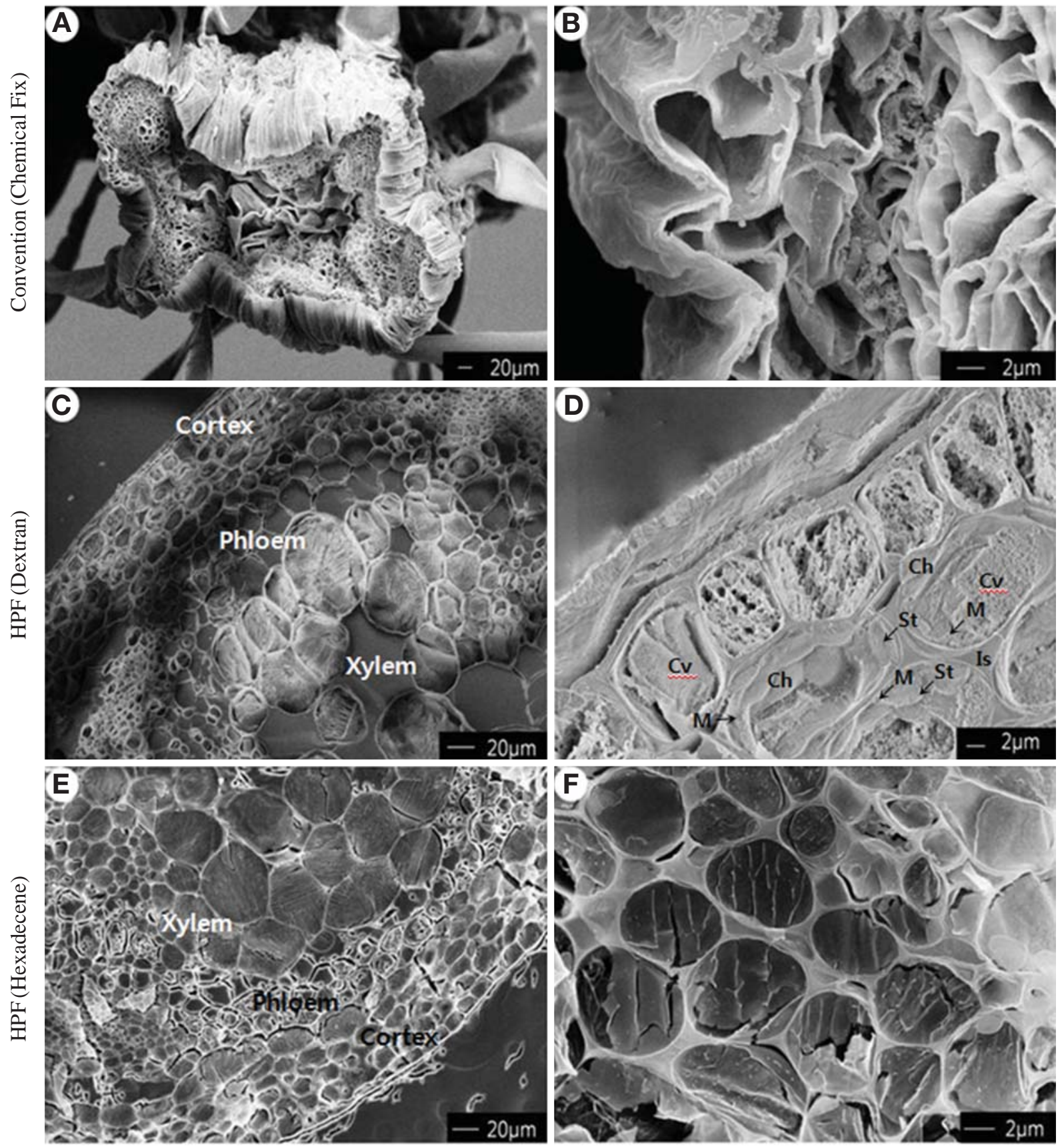

Fig. 2. Scanning electron microscopy (SEM) of Arabidopsis stem cross sections. Samples were prepared by (A and B) convention method, (C and D) cryo-prearation method using dextran, and (E and F) cryo-preparation method using hexadecene. A and B. Stem morphology was completely distorted and shrunk tubular structures and vacuoles. C and D. Cryo-SEM images did not show any damage to the stem structure, such as shrinkage or collapse. E and F. External morphology of stem was preserved without distortion but inner ultrastructures of vacuole and cell were not distinguished due to hexadecene coat. $\mathrm{Ch}$, chloroplast; $\mathrm{Cv}$, cell vacuole; Is, intercellular space; $\mathrm{M}$, mitochondria; St, starch.

가 고정되는 부분의 온도를 $-100^{\circ} \mathrm{C}$ 이하로 유지하여 이동 시키며 액체질소를 지속적으로 보충해 주어 cryo-SEM에 시료가 옮겨질 때까지 적정 온도를 유지하였다.

Cryo-SEM은 $-100^{\circ} \mathrm{C}$ 이하의 온도를 유지하면서 관찰하 였다. 생물 시료의 경우 전자선 손상을 최소화 하는 것이 중
요한데 cryo-SEM에서는 전자선에 큰 영향을 받지 않고, 다 만 파쇄시킨 시편이기 때문에 백금 도포를 고르게 하지 못 하거나 너무 얇게 하게 될 경우 charging effect로 인해 양 질의 이미지를 얻을 수 없다. 따라서 백금 도포의 조건을 시료에 따라 다양하게 변화시키면서 관찰하였다. 이상의 실 
험 방법은 Fig. 1에 간략하게 도식화하였다.

애기장대 줄기의 미세구조를 일반 시료 제작법에 의해 관찰한 결과, 전처리 과정 중 발생한 것으로 보이는 구조적 수축과 변형 현상을 쉽게 확인할 수 있었다. 줄기의 기본 조직인 피층에서 나타난 구조적 변형으로 인하여 관상 구 조물들의 내부 형태의 관찰이 불가능할 뿐만 아니라 피질 및 물관, 체관과 같은 다양한 관상 구조 안의 함유물들 또 한 대부분 소실되어 있었고 엽록체 등 세포내 미세 구조물 들은 전혀 관찰할 수가 없었다(Fig. $2 \mathrm{a} \& \mathrm{~b}$ ). 반면, HPF에 의한 동결 시료의 경우 일반 시료 제작에 의한 시료와 비교 하여 구조적 보전이 뛰어나 애기장대 줄기의 단면에 대한 미세구조의 관찰이 용이하였다(Fig. 2c-f). 즉, 표피층 및 피 질 부분의 관상 구조가 구조적 변형 없이 분명하게 관찰 되 었고, 물관 및 체관 등의 내부 구조와 엽록체 그리고 미토 콘드리아와 녹말 등의 미세구조를 확인할 수 있었다. 특히 $\mathrm{HPF}$ 를 이용한 동결 고정시 동결 보호제로써 $20 \%$ dextran 을 사용하였을 경우 애기장대 줄기의 내부 구조 보전 효과 가 뛰어나 세포내 엽록체와 미토콘드리아 등 미세구조의 판 독이 용이하였으며 액포나 세포질 등의 보전 능력이 뛰어 났다(Fig. 2c \& d). 그러나 1-hexadecene을 사용한 경우 세 포벽 및 관상 구조물의 형태가 유지된 반면에 hexadecene 이 세포 단면과 관상 구조의 내부로 침투하여 세포소기관 들의 미세구조에 대한 관찰이 불가능하였다(Fig. 2e \& f).

Cryo-SEM 분석을 위하여 HPF 장치를 이용할 때 시료의 신선도, 크기와 두께 그리고 carrier의 두께가 freezing quality에 큰 영향을 미칠 수 있으므로 주의하여야 한다. 특히 시 료의 내외에 함유된 수분과 공기 등은 급속 동결 시 결정화 를 유발하므로 이를 방지하기 위하여 열전도를 최적화하고 시료에 대한 결정화를 억제할 수 있도록 세포내 수분 및 공 기 등을 extra-cellular fluid로 치환할 필요가 있다. 이러한 $\mathrm{HPF}$ 처리 시 시료의 열전도 효율 증강과 물리적 손상으로 부터의 보호 목적으로 사용하는 cryo protectant에는 1-hexadecene과 dextran이 보편적으로 사용되고 있다. 1-hexadecene은 transmission fluid로 표면장력이 낮고 liquid나 solid 상태에서 열전도율이 좋은 특징이 있다. 또한 dextran은 antifreezing agents로 보통 $20 \%$ 농도로 사용되며, cryo-section 시 1-hexadecene보다 더 잘 잘리는 것으로 알려져 있다. 따
라서 시료에 맞추어 적절한 cryo-protectant를 사용하는 것 이 중요하다. 본 연구를 통하여 1-hexadecene은 식물의 관상 구조를 관찰하기 위하여 적합하지 않음을 확인하였다. 추가 적으로 고정 방법과 상관없이 ice crystal 생성 및 charging effect는 $\mathrm{HPF}$ 를 이용한 cryo-SEM 관찰 시 매우 중요한 영 향을 미친다. 따라서 샘플의 전처리 및 이동 과정 등에서 ice crystal 생성의 방지를 위해 cryo-transfer를 이용해 $-100^{\circ} \mathrm{C}$ 이하의 온도를 유지하는 것이 중요하다. Charging effect는 관찰하고자 하는 시료에 대한 코팅 조건을 변화시켜 감소시 킬 수 있다.

본 연구는 화학고정 및 일반 SEM 분석에서 발생할 수 있 는 구조적 손상을 최소화 하기 위하여 $\mathrm{HPF}$ 와 freeze fracture 기법을 이용한 cryo-SEM시료 제작법을 소개하고 이를 통한 cryo-SEM 관찰의 우수성을 확인하였다. 따라서 $\mathrm{HPF}$ 와 freeze fracture 기법은 식물의 다양한 관상 구조와 액포 등의 미세구조 관찰을 위한 cryo-SEM 분석에 유용하게 활 용할 수 있을 것으로 기대한다.

\section{참 고 문 헌}

Beckett ND, Porter R: Low-temperature scanning electron microscopy. Ultrastructural Techniques for Microorganisms. Plenum Publishing Corporation, New York, pp. 45-86, 1986.

Boyde A: Biological specimen preparation for the scanning electron microscope: an overview. Proceedings of the Fifth Annual Electron Microscopy Symposium, Chicago, 1972.

Echlin P, Taylor SE: The preparation and X-ray microanalysis of bulk frozen hydrated vacuolated plant tissue. J Microsc 141 : 329-348, 1986

Lee E-J, Moon Y-J, Oh H-W, Kim S-J, Chung Y-H, Kweon H-S, Kim Y-J: Observations of the Cyanobacteria Synechocystis sp. PCC 6803 using cryo-methods and cryo-SEM. Kor J Microse 39 : 65-72, 2009.

Sargent JA: Low temperature scanning electron microscopy: advantages and applications. Scanning Microsc 2 : 835-849, 1988.

Shimoni E, Muller M: On optimizing high-pressure freezing: from heat transfer theory to a new microbiopsy device. J Microsc 192 : 236-247, 1998. 